\title{
Mechanisms underlying 3-bromopyruvate-induced cell death in colon cancer
}

\author{
Yiming Sun ${ }^{1} \cdot$ Zhe Liu $^{1} \cdot$ Xue Zou ${ }^{1}$ - Yadong Lan ${ }^{2} \cdot$ Xiaojin Sun ${ }^{1}$ • \\ Xiu Wang ${ }^{1} \cdot$ Surong Zhao $^{1}$ • Chenchen Jiang ${ }^{3} \cdot$ Hao Liu ${ }^{1}$
}

Received: 19 January 2015 / Accepted: 27 May 2015 /Published online: 9 June 2015

(C) The Author(s) 2015. This article is published with open access at Springerlink.com

\begin{abstract}
Bromopyruvate (3BP) is an energy-depleting drug that inhibits Hexokinase II activity by alkylation during glycolysis, thereby suppressing the production of ATP and inducing cell death. As such, 3BP can potentially serve as an anti-tumorigenic agent. Our previous research showed that 3BP can induce apoptosis via AKT /protein Kinase B signaling in breast cancer cells. Here we found that 3BP can also induce colon cancer cell death by necroptosis and apoptosis at the same time and concentration in the SW480 and HT29 cell lines; in the latter, autophagy was also found to be a mechanism of cell death. In HT29 cells, combined treatment with 3BP and the autophagy inhibitor 3-methyladenine (3-MA) exacerbated cell death, while viability in 3BP-treated cells was enhanced by concomitant treatment with the caspase inhibitor benzyloxycarbonyl-Val-Ala-Asp fluoromethylketone (z-VAD-fmk) and the necroptosis inhibitor necrostatin (Nec)-1. Moreover, 3BP inhibited tumor growth in a SW480 xenograft mouse model. These results indicate that 3BP can suppress tumor growth and induce cell death by multiple mechanisms at the same time and concentration in different types of colon cancer cell by depleting cellular energy stores.
\end{abstract}

Yiming Sun and Zhe Liu contributed equally to this work.

Hao Liu

liuhao6886@foxmail.com

1 Faculty of Pharmacy, Bengbu Medical College, Bengbu 233000, Anhui, People's Republic of China

2 Department of Surgical Oncology, The First Affiliated Hospital of Bengbu Medical College, Bengbu 233004, People's Republic of China

3 School of Medicine and Public Health, Faculty of Health, University of Newcastle, Newcastle, NSW, Australia
Keywords 3-Bromopyruvate - ATP · Apoptosis · Autophagy $\cdot$ Necroptosis

$\begin{array}{ll}\text { Abbreviations } \\ \text { 3BP } & \text { 3-Bromopyruvate } \\ \text { HK } & \text { Hexokinase } \\ \text { 3-MA } & \text { 3-methyladenine } \\ \text { z-VAD- } & \text { Caspase inhibitor benzyloxycarbonyl-Val-Ala- } \\ \text { fmk } & \text { Asp fluoromethylketone } \\ \text { Nec-1 } & \text { Necrostatin-1 } \\ \text { CRC } & \text { Colorectal cancer } \\ \text { RIP1 } & \text { Receptor-interacting protein 1 } \\ \text { RIP3 } & \text { Receptor-interacting protein 3 } \\ \text { LC3 } & \text { Microtubule-associated protein 1 light chain 3 } \\ \text { MCTs } & \text { Monocarboxylate transporters } \\ \text { TNF } & \text { Tumor necrosis factor } \\ \text { MTT } & \text { 3-(4,5-dimethylthiazol-2-yl)-2,5-diphenyltetra- } \\ & \text { zolium bromide } \\ \text { PI } & \text { Propidiumiodide } \\ \text { DAPI } & \text { 4',6-diamidino-2-phenylindole } \\ \text { PBS } & \text { Phosphate Buffered Saline } \\ \text { DMSO } & \text { Dimethylsulfoxide } \\ \text { DMEM } & \text { Dulbecco's Modified Eagle's Medium } \\ \text { DNR } & \text { Daunorubicin }\end{array}$

\section{Introduction}

Colorectal cancer (CRC) is the third most diagnosed cancer worldwide, and there has been extensive research on antitumorigenic drugs for its treatment (Jemal et al. 2011). CRC is typically treated by surgical resection and postoperative adjuvant radio- and chemotherapy. However, the latter is associated with strong side effects and dose-limiting toxicity. As 
such, there is ongoing need for developing less toxic but still effective drugs to treat CRC.

The Warburg effect posits that tumor cells depend on glycolysis to generate ATP even in the presence of oxygen (Warburg 1956). The enzyme hexokinase (HK), a key glycolytic enzyme, is overexpressed in tumor cells and is inhibited by 3-bromopyruvate (Cardaci et al. 2012; da-Silva et al. 2004). It is putative that proton-linked monocarboxylate transporters (MCTs) mediate 3BP uptake. 3BP mediate pyruvylation of GAPDH which decrease ATP and anabolic precursors. Pyruvylated GAPDH could elicite the proapoptotic effects after translocating into the nucleus phenocoping (Cardaci et al. 2012). Inhibition of hexokinaseII by 3BP decreases ATP and NADPH levels, thereby blocking glycolysis in tumor cells and slowing or halting their growth (Chen et al. 2009; Chesney et al. 1999; Galluzzi et al. 2012). 3-BrPA mediated impairment of succinate dehydrogenase (SDH) activity lowers succinate-derived ATP levels and increases ROS production (Cardaci et al. 2012).

Previous study (Leist et al. 1997) indicates that apoptosis is a process depending on ATP, the lack of ATP would result in cell necrosis. Research (Xu et al. 2005) reported cell deaths by 3BP contain apoptosis and necrosis. While massive depletion of ATP leads to necrosis, a moderate decrease leads to induction of cellular autophagy to overcome situations of energetic or metabolic stress (Shoshan 2012). The absence of ATP leads to DNA degradation and ultimately to cell death (Parks et al. 2013). Moreover, mitochondrial permeability is increased by inhibiting HK and the consequent release of cytochrome C activates caspases that induce cellular apoptosis (Ferraro et al. 2008; Zuo et al. 2011). Under apoptosis-deficient conditions or upon infection by certain types of virus, receptorinteracting protein (RIP)1 forms a complex with RIP3 to mediate necroptosis, which is characterized by the activation of autophagy with necrotic features. The formation of this complex requires RIP1 kinase activity, which is inhibited by the small molecule Nec-1 (Degterev et al. 2005; Yuan and Kroemer 2010).

Three forms of cell death are recognized, including apoptosis, cell death associated with autophagy, and necrosis. The latter is typically unregulated, whereas apoptosis and autophagic cell death are considered as two types of programmed cell death (Galluzzi et al. 2012). However, an increasing number of studies have demonstrated that necrosis can also be regulated in a process known as necroptosis (Cho et al. 2009; He et al. 2009; Zhang et al. 2009a). Morphological features of apoptotic cells are chromatin condensation leading to pyknotic nuclei (Schweichel and Merker 1973) and the close packing of cytoplasmic organelles resulting from a loss of cytosol (Bellairs 1961). Autophagic cells are characterized by the appearance of autophagic vacuoles in the cytoplasm. The conversion of microtubule-associated protein 1 light chain (LC)3Ito LC3-IIin the membranes of autophagic bodies is widely used as an autophagosome marker (Kabeya et al. 2000; Tanida et al. 2004; Zhang et al. 2014). Autophagy can be specifically inhibited by 3-MA. Necroptotic cells exhibit a breakdown of the cell membrane and swelling of cellular organelles ( $\mathrm{He}$ et al. 2009).

Our previous work found that 3BP can induce apoptosis via AKT signaling in breast cancer cells (Liu et al. 2014). This was investigated in the present study using SW480 and HT29 human colon carcinoma cell lines. The results showed that $3 \mathrm{BP}$ induces multiple forms of cell death by energy depletion in vitro, which is beneficial to reduce the resistance of the single cell death form by drugs, providing a potential treatment for a special cells, and 3BP possesses anti-tumor ability in vivo, suggesting that $3 \mathrm{BP}$ can be used in the treatment of CRC.

\section{Materials and methods}

\section{Reagents and antibodies}

The compounds 3BP, 3-MA, 3-(4,5-dimethylthiazol-2-yl)-2, 5-diphenyltetrazolium bromide (MTT), and Nec-1 were purchased from Sigma-Aldrich (St. Louis, MO, USA). The caspase inhibitor z-VAD-fmk was purchased from Calbiochem (San Diego, CA, USA). The JC-1(5,5',6,6'-tetrachloro-1,1',3, 3'-tetraethyl-benzimidazolylcarbocyanine iodide) and PI assay kits were purchased from Beyotime Institute of Biotechnology (Wuhan, China) and the ATP Assay kit was from Merck KGaA (Darmstadt, Germany) and An Annexin V FITC/propidium iodide (PI) apoptosis detection kit was purchased from Nanjin KeyGen Biotech (Nanjing, China). The enzyme-linked immunosorbent assay kit for Hexokinase II was purchase from Cloud-Clone Crop (Houston, TX, USA). The following antibodies were used: rabbit monoclonal antibodies against X-linked inhibitor of apoptosis protein (XIAP), cellular inhibitor of apoptosis protein (cIAP)1 (both from Bioss, Hong Kong, China), and cIAP2 (Abgent, Suzhou, China); monoclonal antibodies against LC3, Bcl-2-associated $\mathrm{X}$ protein (Bax), myeloid cell leukemia (Mcl)-1, and B cell CLL/ Lymphoma (Bcl)-2 protein (all from Proteintech, Chicago, IL, USA); and rabbit monoclonal antibodies against RIP1 and 3 and $\beta$-actin and HKII(Santa Cruz Biotechnology, Santa Cruz, CA, USA); Anti-monocarboxylate transporter (MCT)1 antibody and rabbit anti-monocarboxylate transporter (MCT) 4 were obtained from Millipore (Temecula, CA, USA); Antimonocarboxylate transporter (MCT)2 was form Abcam (Cambridge, MA, USA). All reagents were dissolved according to the manufacturer's instructions.

\section{Cell culture}

Human colon carcinoma SW480 and HT29 cells were obtained from the American Type Culture Collection (Manassas, 
VA, USA) and were passaged for less than half a year. Cells were grown in high-glucose Dulbecco's Modified Eagle's Medium (DMEM) supplemented with $10 \%$ fetal bovine serum, $100 \mathrm{U} / \mathrm{ml}$ penicillin, and $100 \mu \mathrm{g} / \mathrm{ml}$ streptomycin at $37^{\circ} \mathrm{C}$ in $95 \%$ air and $5 \% \mathrm{CO}_{2}$.

\section{MTT assay}

Cells were seeded in a 96-well plate at a density of $6 \times 10^{3}$ cells per well and treated with different concentrations of $3 \mathrm{BP}$. At 24, 48, and $72 \mathrm{~h}$, MTT ( $5 \mathrm{mg} / \mathrm{ml}$ in phosphate-buffered saline, PBS) was added for $4 \mathrm{~h}$ at $37{ }^{\circ} \mathrm{C}$. After $4 \mathrm{~h}$, the solution was replaced with $150 \mu$ of dimethylsulfoxide (DMSO, Biosharp, Hefei, China) and $30 \mathrm{~min}$ later, cell viability was determined by measuring absorbance at a wavelength of $490 \mathrm{~nm}$ using a microplate reader (Synergy HT, BioTek, Vermont, U.S.A).

\section{Colony formation assay}

Cells were seeded in 6-well plates at $1 \times 10^{5}$ cells per well and incubated for $24 \mathrm{~h}$, then treated with various concentrations of 3BP for $24 \mathrm{~h}$. The medium was replaced with $2 \mathrm{ml}$ fresh medium and cells were cultured for 5 more days, then fixed with paraformaldehyde for $10 \mathrm{~min}$ at $-20{ }^{\circ} \mathrm{C}$ followed by staining with $2 \%$ crystal violet for $20 \mathrm{~min}$.

\section{Flow cytometry}

Prior to $3 \mathrm{BP}$ treatment, $2 \times 10^{5}$ cells per well were seeded in a 12 -well plate for $24 \mathrm{~h}$. At exponential growth phase, cells were treated with different concentrations of 3BP $(40,80$, 160 , and $320 \mu \mathrm{mol} / \mathrm{L}$ ) for $24 \mathrm{~h}$, which was followed by PI staining and Accuri C6 flow cytometry (BD Biosciences, State of New Jersey, U.S.A). In addition, annexin-V FITC/PI staining was carried out according to the manufacturer's instructions to detect cellular apoptosis.

\section{Nuclear staining}

Cells $\left(2 \times 10^{6}\right)$ were seeded in a 6-well plate for $24 \mathrm{~h}$ until exponential growth phase, then treated with $3 \mathrm{BP}(0,40,80$, 160 , and $320 \mu \mathrm{mol} / \mathrm{L}$ ) for $48 \mathrm{~h}$. Cells were harvested and washed twice with cold PBS, then fixed with $4 \%$ ethanol for $30 \mathrm{~min}$ at room temperature, followed by two washes with PBS and a 1 min incubation in $100 \mu l$ of DAPI solution $(2 \mu \mathrm{g} / \mathrm{ml})$. Cell morphology was evaluated using a IX71 fluorescence microscope (Olympus, Tokyo, Japan). Cells showing chromatin condensation and nuclear fragmentation were determined to be apoptotic.

\section{Determination of ATP}

ATP levels were measured using a luminescence-based ATP Assay kit. The assay uses luciferase to catalyze the generation of a fluorescent signal from ATP, luciferin, and oxygen; with the degree of fluorescence proportional to the amount of ATP. Cells $\left(2 \times 10^{5}\right)$ seeded in a 12 -well plate for $24 \mathrm{~h}$, were incubated with various concentrations of $3 \mathrm{BP}$ for $5 \mathrm{~h}$ at $37^{\circ} \mathrm{C}$, with untreated cells serving as a control group. After incubation, cells were collected and homogenized in RIPA lysis buffer for $10 \mathrm{~min}$ on ice. Cell lysates were centrifuged at $13,225 \times \mathrm{g}$ for 5 min at $4{ }^{\circ} \mathrm{C} .100 \mu \mathrm{l}$ of nucleotide-releasing buffer per well and $1 \mu \mathrm{l}$ ATP-monitoring enzyme per well were added to a 96well plate, $30 \mu \mathrm{l}$ of each suspension were transferred to each well; and after a $60 \mathrm{~s}$ incubation at $25{ }^{\circ} \mathrm{C}$, the signal was measured using a Luminoskan luminometer (Thermo Scientific, Atlanta, GA, USA).

\section{Determination of mitochondrial membrane potential}

Cells were seeded at a density of $2 \times 10^{5}$ cells per well in 12 well-plates and treated with various concentrations of 3BP. After $24 \mathrm{~h}$, changes in mitochondrial membrane potential were determined by staining cells with the cationic dye JC-1 using a kit according to the manufacturer's instructions. Green and red fluorescence was detected on the 1 and 2 channels, respectively, of an IX71 fluorescence microscope.

\section{Western blot analysis}

Cells were collected and homogenized in RIPA lysis buffer for $30 \mathrm{~min}$ on ice. Cell lysates were centrifuged at $13,225 \times \mathrm{g}$ for $30 \mathrm{~min}$ at $4{ }^{\circ} \mathrm{C}$. Proteins were separated on a $12 \%$ sodium dodecyl sulfate polyacrylamide gel and transferred to a nitrocellulose membrane (Universal Hood II, BioRad Laboratories, Hercules, CA, U.S.A), which was incubated with primary antibodies overnight at $4{ }^{\circ} \mathrm{C}$ followed by the appropriate secondary antibody, with $\beta$-actin used as a loading control.

\section{Enzyme-linked immunosorbent assay kit for Hexokinase II}

Cells were seeded at a density of $2 \times 10^{5}$ cells per well in 12 well-plates and treated with various concentrations of $3 \mathrm{BP}$ for $24 \mathrm{~h}$ at $37^{\circ} \mathrm{C}$, with untreated cells serving as a control group. After incubation, cells were collected and homogenized in $1 \%$ triton- 100 for $10 \mathrm{~min}$ on ice. Cell lysates were centrifuged at $1000 \times \mathrm{g}$ for $20 \mathrm{~min}$ at $4{ }^{\circ} \mathrm{C}$. Detect the concentration of HKII according to the manufacturer's instructions. 


\section{Evaluation of cell death type by electron microscopy}

Cells were fixed with $3 \%$ glutaraldehyde and $2 \%$ paraformaldehyde in $0.1 \mathrm{M}$ PBS (pH 7.4) overnight at $4{ }^{\circ} \mathrm{C}$, then postfixed with $1 \%$ osmium tetroxide for $1.5 \mathrm{~h}$, washed, and stained with $3 \%$ aqueous uranyl acetate for $1 \mathrm{~h}$ before dehydration in a graded series of ethanol and acetone and embedding in Araldite. Ultrathin sections were cut on a Reichert ultramicrotome (Leica, Wetzlar, Germany), stained with $0.3 \%$ lead citrate, and analyzed by TEM (Olympus JEOL, Peabody, MA, USA).

\section{Xenograft model}

Female nude mice (BALB/c) 4-5 weeks of age and weighing 18-20 g were purchased from the animal experimental center of Beijing vitalriver and maintained under specific pathogenfree conditions. The experimental protocol was approved by the ethics committee of Bengbu Medical College and was carried out in accordance with the Guidance and Suggestions for the Care and Use of Laboratory Animals published by The Ministry of Science and Technology of China. SW480 cell suspensions with $>90 \%$ viability were used for injections. Mice were grafted subcutaneously in the left flank with $10^{7}$ cells resuspended in $0.2 \mathrm{ml}$ sterile DMEM. Mice were randomized into $3 \mathrm{BP}(8 \mathrm{mg} / \mathrm{kg})$, DNR positive control $(0.8 \mathrm{mg} / \mathrm{kg})$, and PBS negative control groups $(n=5$ per group) when tumor volume reached approximately $100 \mathrm{~mm}^{3}$. Group the implantation model using stratified random grouping according to the tumor size. Tumors were measured with a caliper and volume was calculated using the formula: $0.5 \times a \times b^{2}$, where $a$ and $b$ are tumor length and width, respectively. Tumors were stored in $4 \%$ formalin solution, embedded in paraffin, and cut into sections that were stained with hematoxylin and eosin ( $\mathrm{H} \& \mathrm{E})$.

\section{Statistical analysis}

Independent experiments were performed in triplicate. Data are expressed as the mean \pm SEM of three experiments. SPSS v.16.0 software (SPSS Inc., Chicago, IL, USA) was used for data analysis. Half-maximal inhibitory concentration (IC50) was calculated by probit regression analysis. Mean differences were evaluated by t-test analysis of variance. ${ }^{*} p<0.05$ was considered statistically significant.

\section{Results}

\section{BP selectively inhibits colon cancer cell viability}

SW480 cells had greater sensitivity to 3BP than HT29 cells, and viability decreased in a dose-dependent manner
(Fig. 1a and b). In addition, colony formation in both cell types was inhibited by increasing concentrations of $3 \mathrm{BP}$ $(10-50 \mu \mathrm{mol} / \mathrm{L})($ Fig. 1c), indicating that 3BP efficiently inhibits colon cancer cell growth.

\section{BP lowers HKII level and mediate MCTs}

ELISA results suggested that HKII was reduced as the 3BP concentration dependence (Fig. 2a). Cellular ATP levels was reduced by treatment with 3BP (Fig. 2b). These data indicate that and induces cell death by decrease ATP level. Western blotting results showed that with the increase of concentrations of 3BP the expression of MCT1, MCT2 and HKIIwas reduced, in turn MCT2 expression did not change basically (Fig. 2c), The results indicated the 3BP transporters into colon cancer cells through MCTs, influencing the expression of HKII.

\section{BP induces apoptosis in colon cancer cells}

JC-1 staining was used to detect mitochondrial membrane potential (Fig. 3a). Treated cells exhibited condensed and fragmented nuclei, which are indicative of apoptosis, and 4, 6-diamidine-20-phenylindole dihydrochloride (DAPI) staining (Fig. 3b), Annexin-V FITC/PI staining confirmed that 3BP induced apoptosis in SW480 and HT29 cells (Fig. 3c). To investigate the mechanism by which $3 \mathrm{BP}$ induces cell death, TEM examination revealed shrinkage, blebbing, nuclear fragmentation, and chromatin condensation in apoptotic cells (Fig. 4a); these effects were abolished by treatment with the apoptosis inhibitor z-VAD-fmk (Fig. 4b). The induction of apoptosis in colon cancer cells by $3 \mathrm{BP}$ was confirmed by the downregulation of XIAP, cIAP1, cIAP2, Mcl-1, and Bcl-2 protein levels and the upregulation of Bax protein level (Fig. 4c).

\section{BP induces necroptosis in colon cancer cells}

Interesting, the TEM analysis revealed the presence of necroptotic cells following 3BP treatment, which are characterized by an absence of typical nuclear fragmentation, organelle (especially mitochondrial) swelling, and loss of plasma membrane integrity (Fig. 5a). The viability of 3BP-treated cells was rescued by application of the necroptosis inhibitor Nec-1 (Fig. 5b), as evidenced by the downregulation of RIP1 protein (Fig. $5 \mathrm{c}$ ). These data indicate that $3 \mathrm{BP}$ induces necroptosis in colon cancer cells.

\section{BP induces autophagy in colon cancer cells}

Treatment with 3BP induced autophagy in HT29 cells, as evidenced by the appearance of autophagic vacuoles in the cytoplasm (Fig. 6a). The upregulation of LC3-II protein was also observed in 3BP-treated cells (Fig. 6b), indicating that 
Fig. $13 \mathrm{BP}$ selectively inhibits colon cancer cell viability. a SW480 and HT29 cells were treated with $40,80,160$, or $320 \mu \mathrm{mol} / \mathrm{L} 3 \mathrm{BP}$ for 24,48 , or $72 \mathrm{~h}$; cell viability was analyzed by the MTT assay. b SW480 and HT29 cells were treated with various concentrations $3 \mathrm{BP}(80$, 160 , or $320 \mu \mathrm{mol} / \mathrm{L}$ ) for $24 \mathrm{~h}$ and morphology was examined by light microscopy with differential interference contrast optics.

Representative images are shown. c SW480 cells were treated with 0 (A), 10 (B), 20 (C), or 30 (D) $\mu \mathrm{mol} / \mathrm{L}$ and HT29 cells were treated with 0 (A), 30 (B), 40 (C), or 50 (D) $\mu \mathrm{mol} / \mathrm{L} 3 \mathrm{BP}$ for 5 days. Data represent mean \pm SEM of three independent experiments
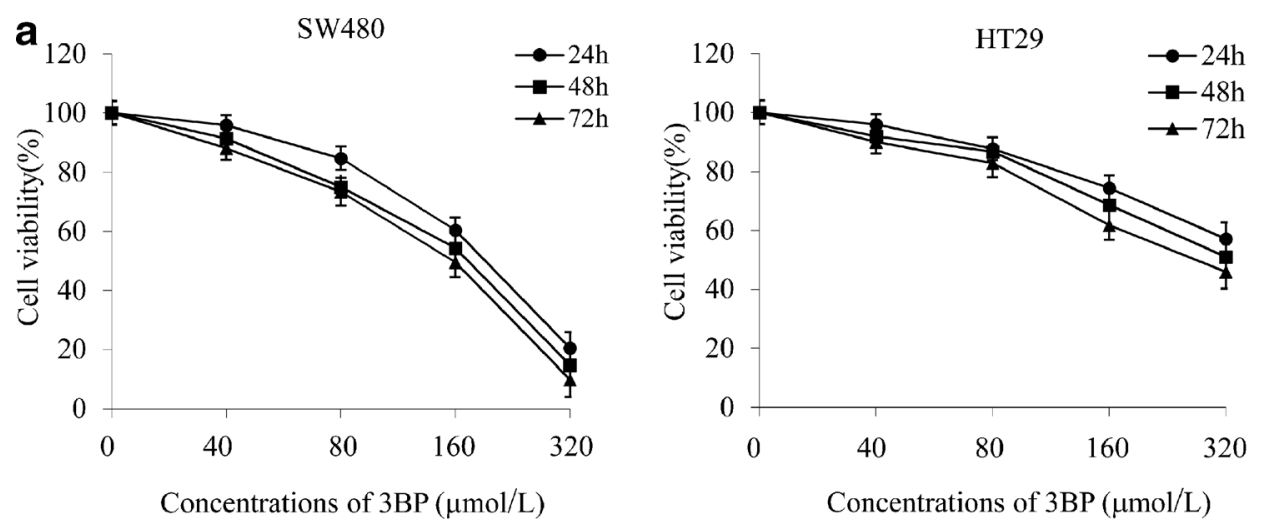

\section{b}

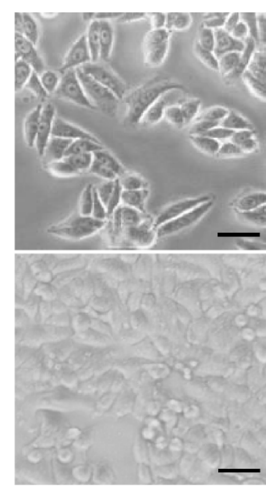

Control

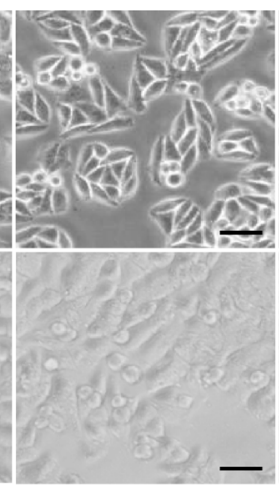

80

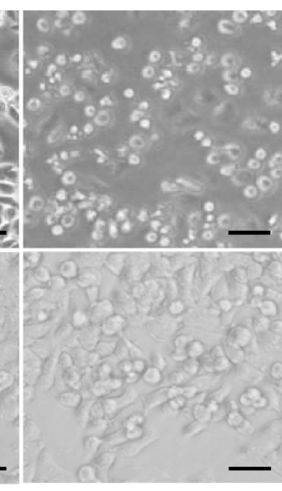

160

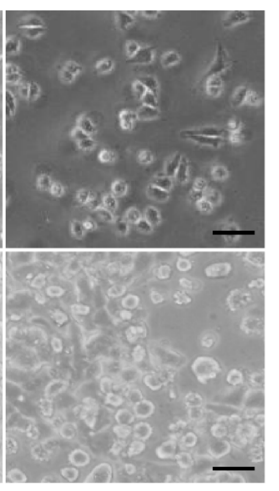

320
Concentrations of 3BP $(\mu \mathrm{mol} / \mathrm{L})$

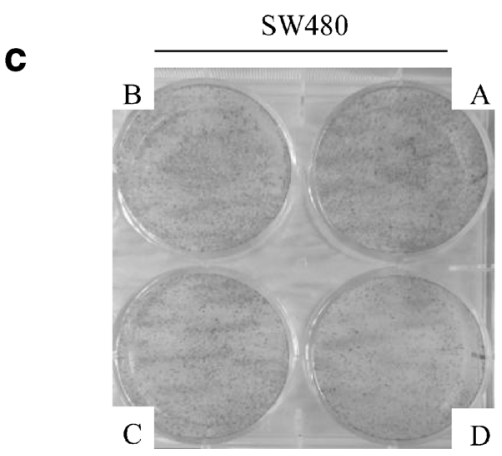

SW480

HT29<smiles>C[18O][18O]</smiles>

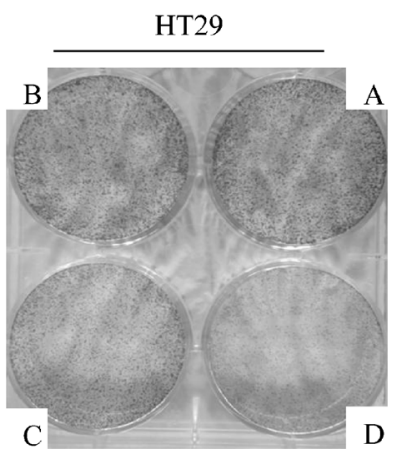

autophagy was induced. Inhibiting autophagy with 3-MA enhanced cell death in 3BP-treated cells, suggesting that autophagy normally protects tumor cells against the cytotoxic effects of 3BP (Fig. 6c).

\section{BP treatment inhibits tumor growth in a mouse model}

The in vivo efficacy of 3BP was evaluated in a xenograft mouse model generated by injecting SW480 cells into nude mice. Treatment with PBS, 3BP $(8 \mathrm{mg} / \mathrm{kg})$ and daunorubicin (DNR; $0.8 \mathrm{mg} / \mathrm{kg}$ ) was initiated when tumor volume reached approximately $100 \mathrm{~mm}^{3}$, 3BP prevented tumor growth (Fig. 7a). On day 28, the average tumor volumes in 3BP and DNR-treated groups $\left(890 \pm 260\right.$, and $790 \pm 200 \mathrm{~mm}^{3}$, respectively) were significantly lower than in vehicle-treated control mice $\left(1750 \pm 374 \mathrm{~mm}^{3}\right)$ (Fig. $\left.7 b\right)$. H \& E staining of the tumors showed that there were rich blood vessels and large atypia nucleus in the tissue in control group, while chaotic distribution of blood vessel, karyopyknosis, inflammatory cell infiltration in experimental group, indicating 3BP induced extensive necrosis and inhibited tumor growth (Fig. 7c), providing evidence for its anti-tumorigenic action in vivo.

\section{Discussion}

Tumorigenesis is characterized by mitochondrial dysfunction, hypoxia, tumor gene expression, and abnormal expression of 

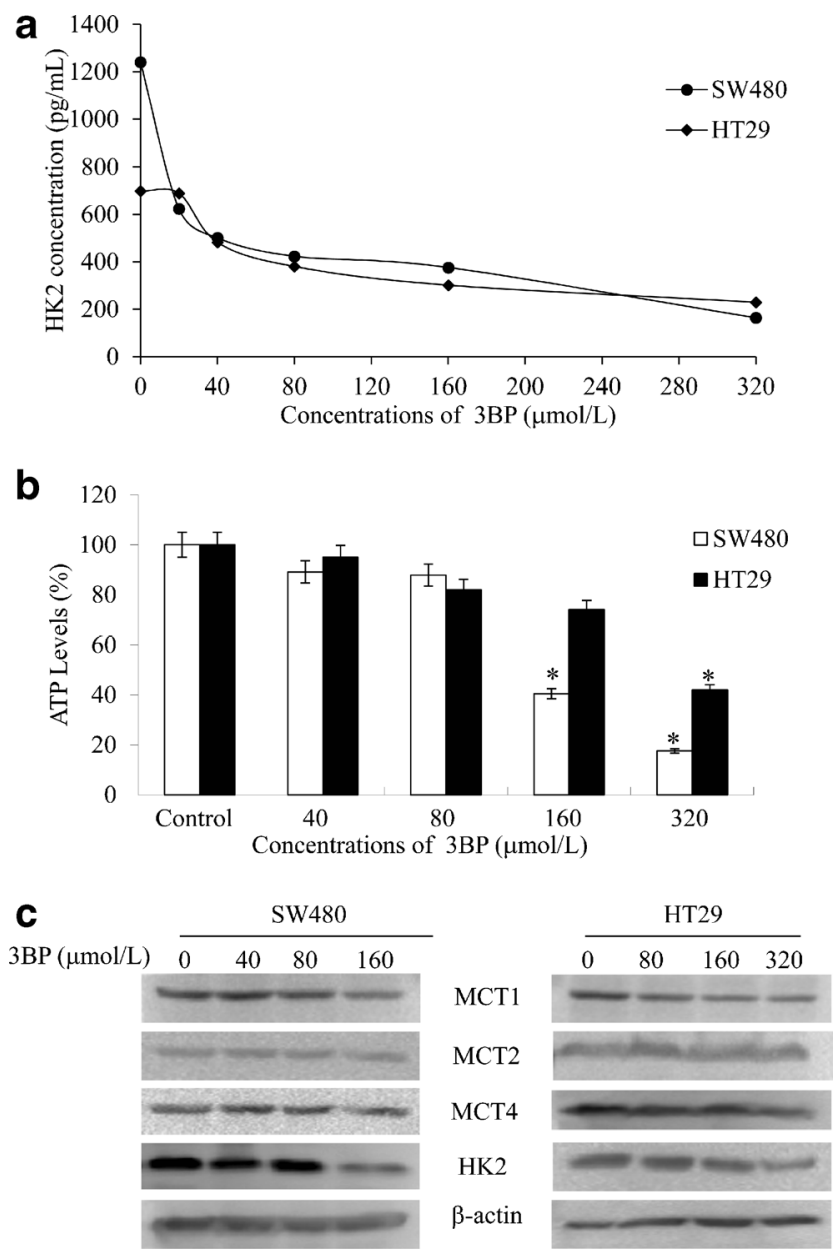

Fig. $23 \mathrm{BP}$ induces HKII and ATP reduction via MCTs transportation in colon cancer cells. a SW480 and HT29 cells were treated with indicated concentrations of 3BP for $24 \mathrm{~h}$, and HKII level were assessed by Enzymelinked immunosorbent assay kit. b Intracellular ATP levels were measured in SW480 and HT29 treated with 40, 80, 160, or $320 \mu \mathrm{mol} / \mathrm{L}$ 3BP for $5 \mathrm{~h}$. control. c SW480 and HT29 cells treated with various concentrations of $3 \mathrm{BP}$ for $24 \mathrm{~h}$ were subjected to HKII level and MCTs by Western blot analysis, $\beta$-actin served as loading control. Data represent mean \pm SEM of three independent experiments. ${ }^{*} p<0.05$ vs

metabolic enzymes (Warburg 1928). Tumor cells utilize ATP generated by glycolysis, which is less efficient than oxidative phosphorylation; as such, tumor cells consume more glucose (i.e., have higher glycolytic activity) than normal cells. As such, inhibiting glycolysis is a potential strategy for killing cancer cells (Simonnet et al. 2002).

As an inhibitor of glycolysis, 3BP is known to have an antitumorigenic function (Levy et al. 2012; Zhang et al. 2009b) in liver and breast cancers and other malignant tumors (Ganapathy-Kanniappan et al. 2010; Geschwind et al. 2002; Liu et al. 2009; Ota et al. 2013). We provide here the evidence for $3 \mathrm{BP}$ as an inhibitor colon cancer cell growth both in vitro and in vivo, which is accomplished by multiple cell death mechanisms, namely apoptosis, necroptosis, and autophagy (Clarke 1990). Programmed cell death is executed via specific intracellular biochemical pathways; apoptosis and necrosis are two such mechanisms that play significant roles in development and the maintenance of homeostasis in metazoans (Festjens et al. 2006), and their dysregulation is linked to various human diseases (Lockshin and Zakeri 2007). Necroptosis is a programmed and regulated form of necrotic cell death that is induced when a noxious stimulus is insufficient to trigger apoptosis in a cell. In such cases, tumor necrosis factor (TNF)- $\alpha$ activates TNF receptor (R) 1 , which recruits RIP1 and other factors to form complex I, consisting of RIP1, RIP3, caspase-8, and Fas-associated death domain protein. These proteins dissociate from TNFR1 and RIP1 and are found in the cytosol as complex IIb, which is an effector of necroptosis (Lukens et al. 2013; Thapa et al. 2013). Caspase activation during apoptosis is accomplished through the extrinsic and intrinsic pathways. The former is activated by the binding of various cytokines such as TNF- $\alpha$, TNF-related apoptosis-inducing ligand, and cluster of differentiation 95 to their respective receptors, leading to caspase- 8 activation (Peter and Krammer 2003). The intrinsic pathway is activated following the release of proteins such as cytochrome $\mathrm{c}$ and Smac/Diablo from the mitochondrial intermembrane space into the cytosol, which then activate caspase-9 and relieve IAP-mediated inhibition of effector proteins (Du et al. 2000; Li et al. 1997; Verhagen et al. 2000). Activated caspase-8 and -9 subsequently cleave and activate several downstream caspases including caspase- 3 and -7 , which in turn cleave intracellular substrates, resulting in apoptosis.

Autophagy is a major intracellular pathway for the degradation and recycling of unused but long-lived proteins, damaged organelles, and invasive pathogens (Mizushima and Komatsu 2011) that functions in several organs, including the brain, heart, hematopoietic cells, and kidney (Komatsu et al. 2006; Mortensen et al. 2011; Takahashi et al. 2012). Mice lacking essential autophagy factors die within 1 day of birth (Kuma et al. 2004). Although it is essential for normal cell function and survival, autophagy can also be exploited by tumor cells for treatment resistance (Jin and White 2008; Mathew and White 2011). Activation of autophagy enhances cell survival (Narendra et al. 2008), and therefore combining standard chemotherapy with an autophagy inhibitor could potentially accelerate tumor cell death (Mathiasen and Jaattela 2002).

It is putative that proton-linked monocarboxylate transporters (MCTs) mediate 3BP uptake. The expression of MCT1 and MCT4 were decreased, possibly due to 3BPinduced cell death, cell membrane cracking, resulting in lower membrane transporters. We guess that inhibition of HKII by 3BP might decreases ATP levels, thereby blocking glycolysis in tumor cells and slowing or halting their growth.

The results of this study showed that 3BP has potent inhibitory effects on colon cancer tumor growth that are comparable to those of DNR. Interestingly, 3BP treatment induced 

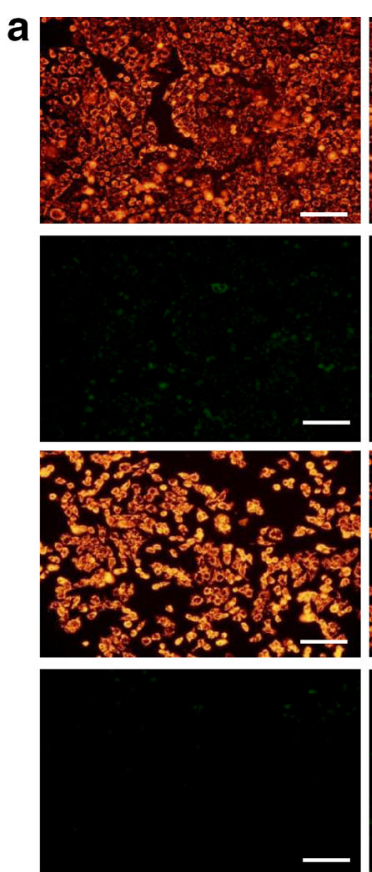

Control

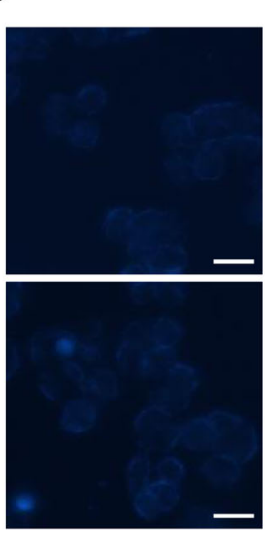

Control
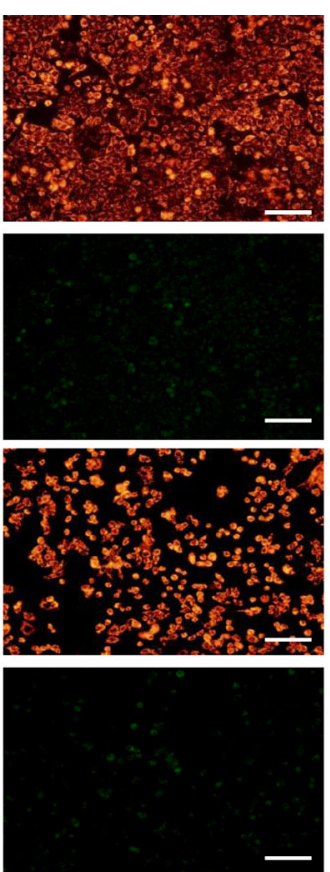

80

Conce
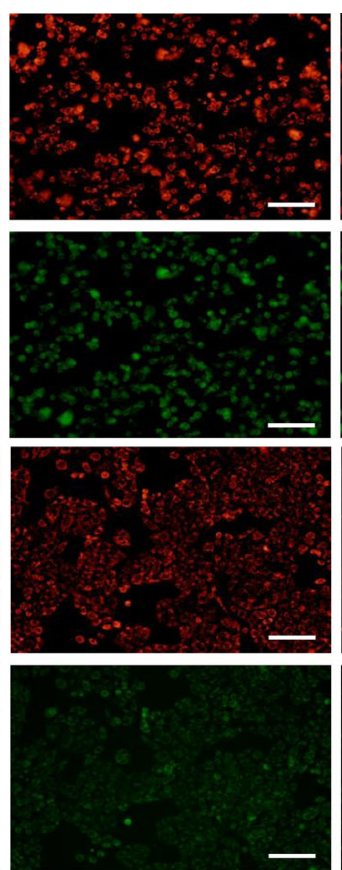

160

$\mathrm{PP}(\mu \mathrm{mol} / \mathrm{L})$
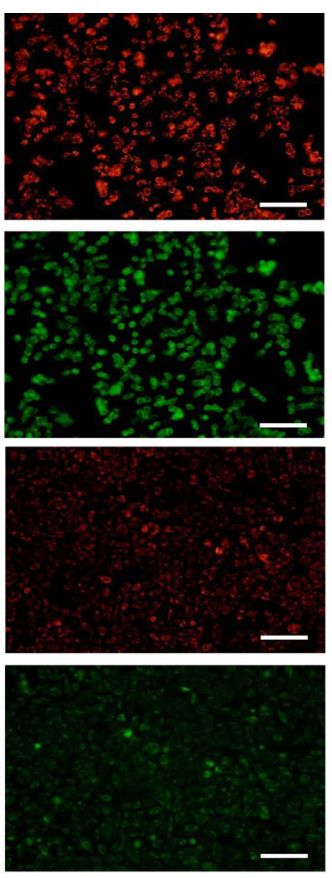

320

$100 \mu \mathrm{m}$

SW480

HT29
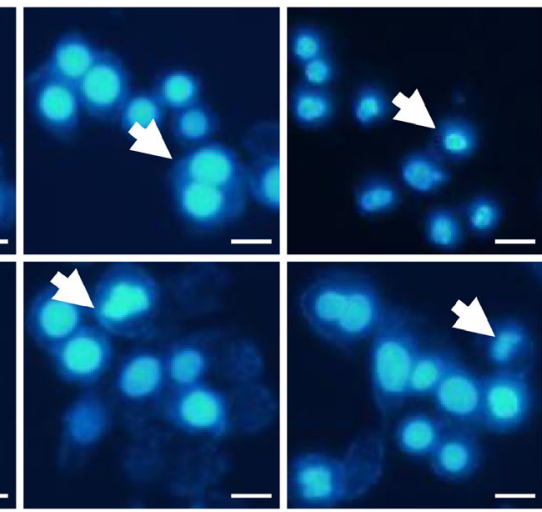

SW480

HT29

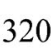

320

\begin{abstract}
160
\end{abstract}
80

Concentrations of $3 \mathrm{BP}(\mu \mathrm{mol} / \mathrm{L})$

C

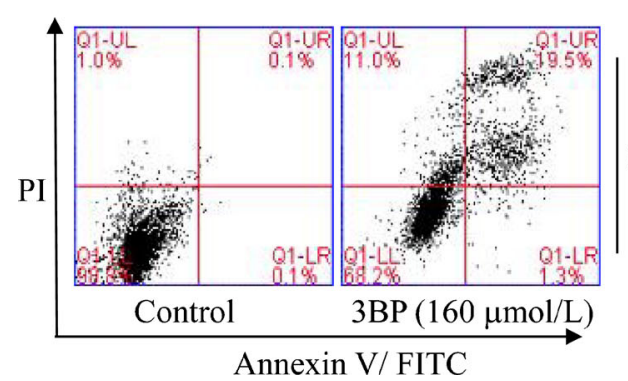

Fig. 3 3BP-induced apoptosis in colon cancer cells. a SW480 and HT29 cells were treated with indicated concentrations of 3BP for $24 \mathrm{~h}$, and the mitochondrial membrane potential were assessed by JC-1 staining and fluorescence microscopy. b SW480 and HT29 cells were treated with indicated concentrations of $3 \mathrm{BP}$ for $48 \mathrm{~h}$, and nuclei were stained with

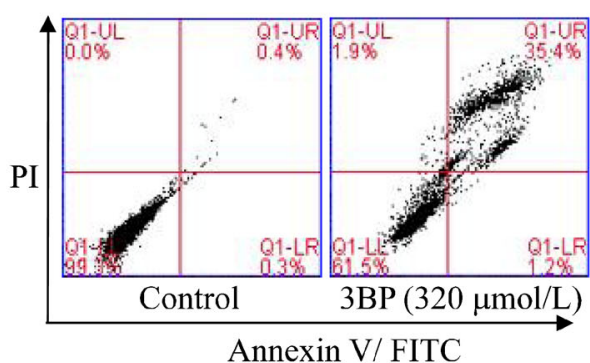

HT29

DAPI and visualized by fluorescence microscopy. White arrowheads indicate apoptotic cells. c SW480 and HT29 cells were treated with indicated concentrations of $3 \mathrm{BP}$ for $24 \mathrm{~h}$, and cells were determined using flow cytometry of PI/Annexin V-stained cells. Data represent mean \pm SEM of three independent experiments 
Fig. 4 3BP-induced apoptosis in colon cancer cells. a Electron microscopy of cells treated for $24 \mathrm{~h}$ with Control, 160 or $320 \mu \mathrm{mol} / \mathrm{L} 3 \mathrm{BP}$, white arrowheads denote chromatin pyknosis in the cells treated with 3BP. b Viability of SW480 or HT29 cells treated with DMSO, 3BP $(160$ or $320 \mu \mathrm{mol} / \mathrm{L}), 3 \mathrm{BP} / \mathrm{z}-$ VAD $(20 \mu \mathrm{mol} / \mathrm{L}$, $)$ was analyzed by MTT assay. Both cells were pretreated with $\mathrm{z}-\mathrm{VAD} 1 \mathrm{~h}$ before treatment with $3 \mathrm{BP} / z-\mathrm{VAD}$. c SW480 and HT29 cells treated with various concentrations of $3 \mathrm{BP}$ for $24 \mathrm{~h}$ were subjected to apoptosis-related proteins by Western blot analysis, $\beta$-actin served as loading control. Data are representative of three independent experiments, ${ }^{*} p<0.05$
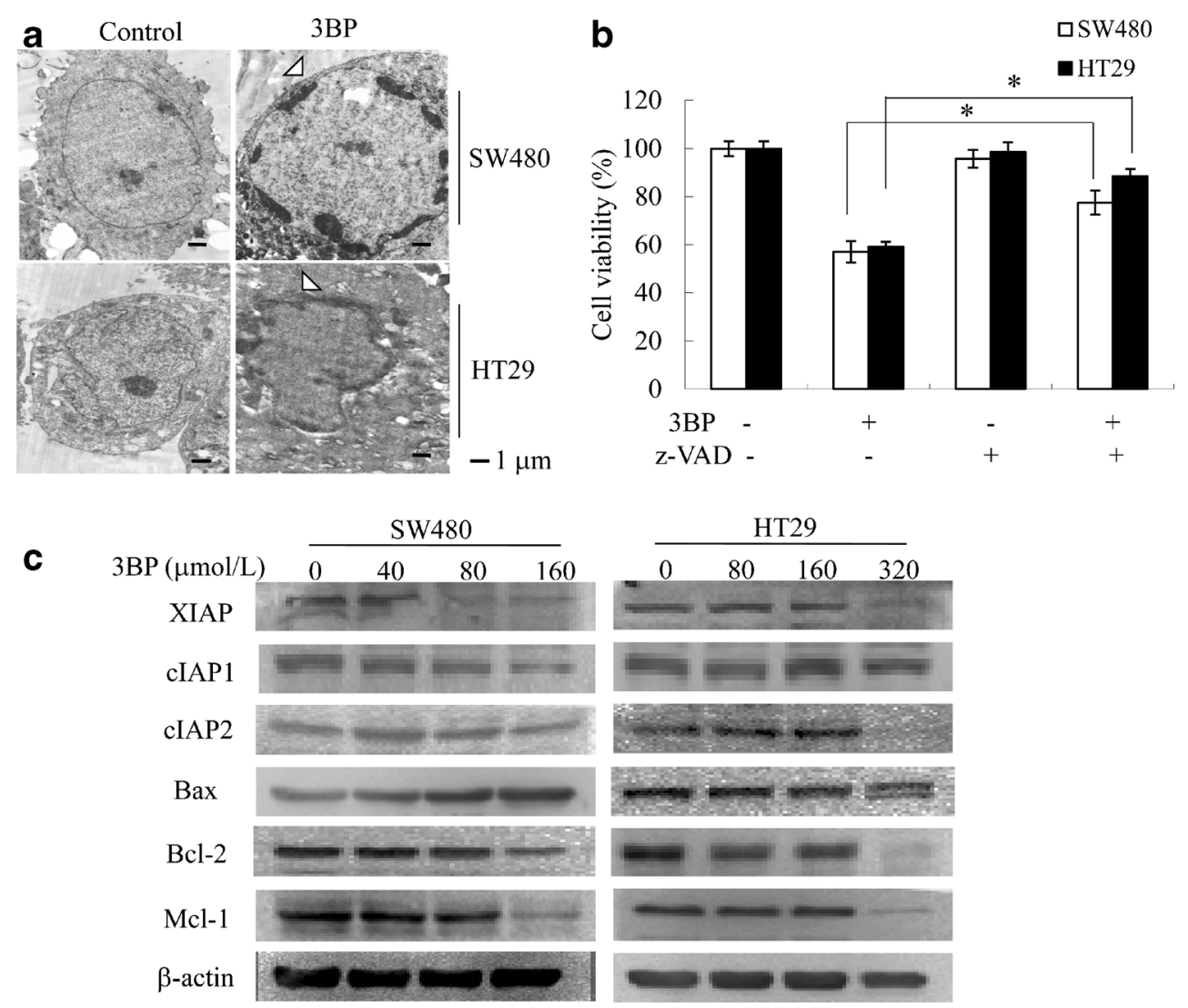

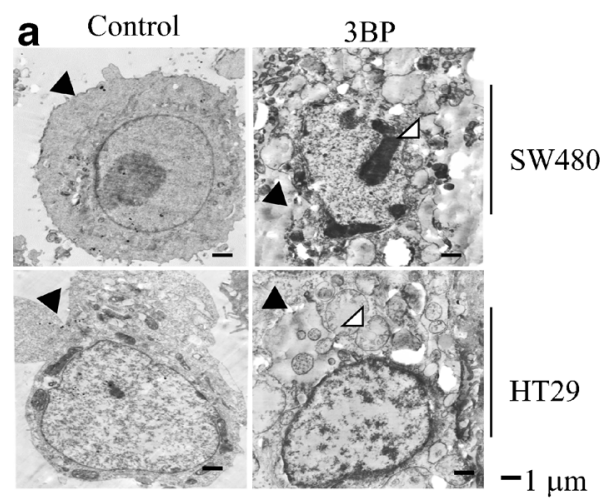

C

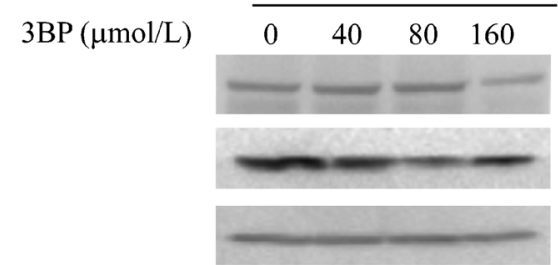

Fig. 5 3BP-induced necroptosis in colon cancer cells. a Electron micrographs of cells treated for $24 \mathrm{~h}$ with 160 or $320 \mu \mathrm{mol} / \mathrm{L} 3 \mathrm{BP}$ or the vehicle dimethylsulfoxide (DMSO; control). Black arrowheads indicate cell membrane integrity in control cells and membrane breakdown in 3BP-treated cells; white arrowheads indicate swelling of cellular organelles in 3BP-treated cells. b SW480 or HT29 cell viability following treatment with $3 \mathrm{BP}(160$ or $320 \mu \mathrm{mol} / \mathrm{L}), 3 \mathrm{BP} / \mathrm{Nec}-1$
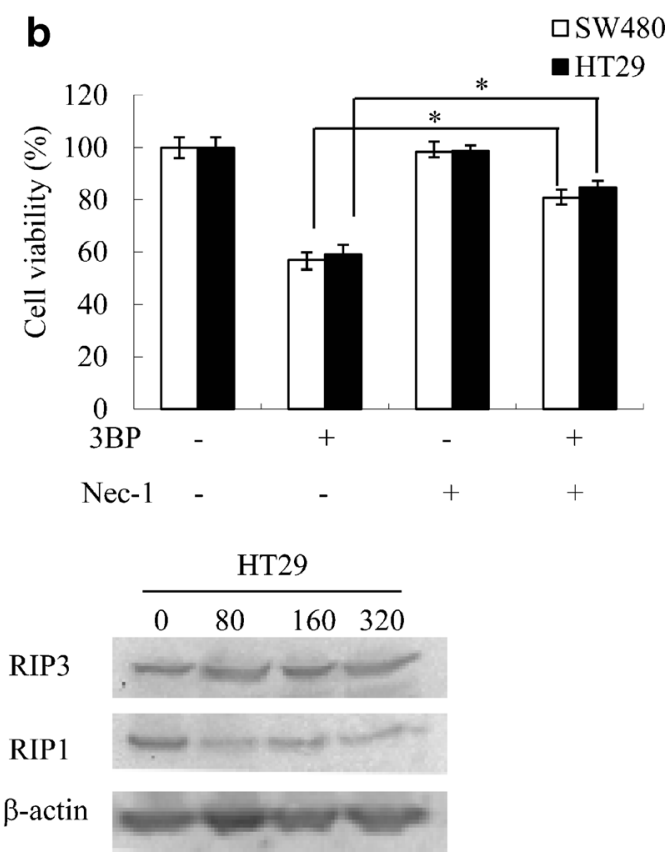

( $20 \mu \mathrm{mol} / \mathrm{L})$, or DMSO, as analyzed by the MTT assay. Both cells were pretreated with Nec-1 $1 \mathrm{~h}$ before treatment with 3BP/Nec-1. c SW480 and HT2 9 cells treated with indicated concentrations of $3 \mathrm{BP}$ for $24 \mathrm{~h}$ were analyzed for the expression of necroptosis-related proteins by western blotting, with $\beta$-actin serving as a loading control. Data represent mean \pm SEM of three independent experiments, ${ }^{*} p<0.05$ 


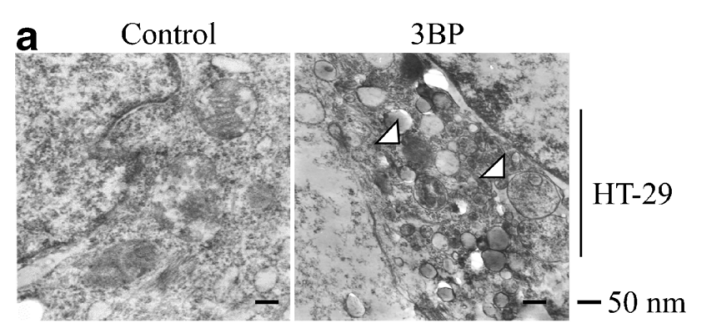

b
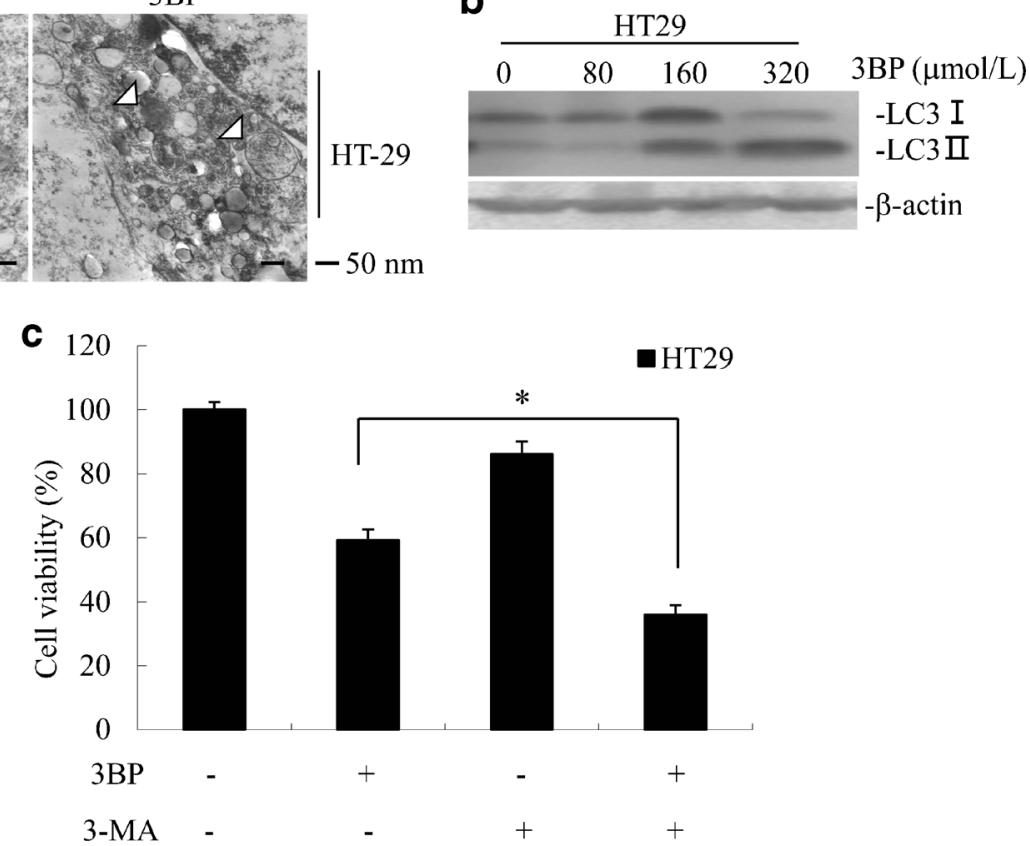

Fig. 6 3BP-induced autophagy in colon cancer cells. a Electron micrographs of HT-29 cells treated for $24 \mathrm{~h}$ with $320 \mu \mathrm{mol} / \mathrm{L} 3 \mathrm{BP}$ or the vehicle dimethylsulfoxide (DMSO; control). White arrowheads indicate autophagosomes. b HT29 cells treated with 3BP $(320 \mu \mathrm{mol} / \mathrm{L})$ for $24 \mathrm{~h}$ were analyzed for the expression of autophagy-related proteins

by western blotting, with $\beta$-actin serving as loading control. $\mathbf{c}$ HT29 cell viability following treatment with DMSO, 3BP $(320 \mu \mathrm{mol} / \mathrm{L}), 3 \mathrm{BP} / 3-$ MA $(5 \mathrm{mmol} / \mathrm{L})$, as analyzed by the MTT assay. Cells were pretreated with 3-MA $1 \mathrm{~h}$ before treatment with 3BP/3-MA. Data represent mean \pm SEM of three independent experiments, ${ }^{*} p<0.05$

autophagy in HT29 but not in SW480 cells; the reasons for this difference between cells lines is unclear, and will require further investigation. Moreover, the observation that the autophagy inhibitor 3-MA potentiated 3BP-induced cell death suggests that autophagy provides a survival advantage for energy-depleted tumor cells. For instance, the necroptosis inhibitor Nec-1 and z-VAD-fmk rescued cell viability that was reduced by 3BP treatment. If cellular energy shortage is exacerbated by suppressing the energy-generating glycolytic pathway in HT29 cells, it is possible that autophagy is insufficient to rescue cells from irreversible cell death but could enable tumor cells to survive.
Fig. 7 in vivo efficacy of 3BP in a nude mouse model. a SW480 cells were subcutaneously injected into the right flank of mice receiving $200 \mu \mathrm{L}$ vehicle, $3 \mathrm{BP}(8 \mathrm{mg} / \mathrm{kg})$, or DNR $(0.8 \mathrm{mg} / \mathrm{kg})$ treatment every 4 days by intraperitoneal injection. Mice were sacrificed after 28 days. b Representative tumors from each treatment group. Data represent mean \pm SEM $(n=5)$. c H\&E staining in vivo a

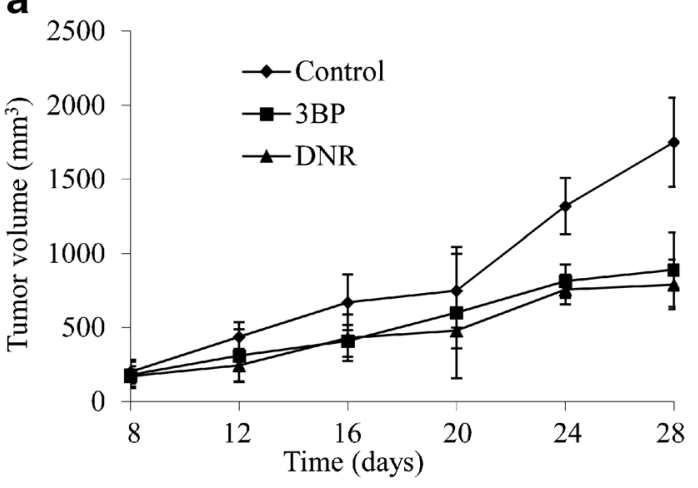

b

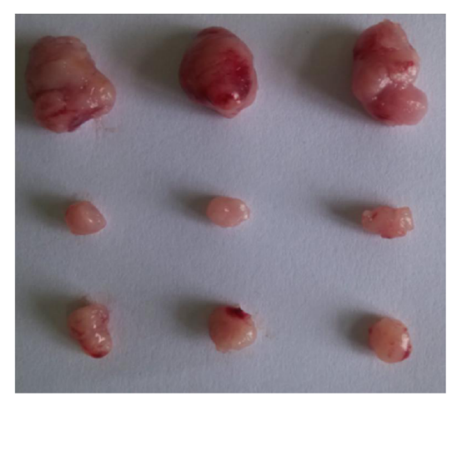

-Control

-DNR

$-3 \mathrm{BP}$

C

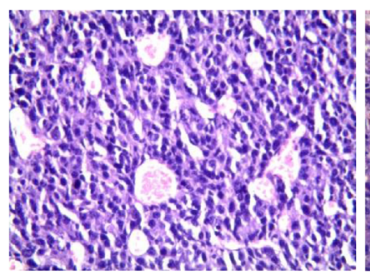

Control

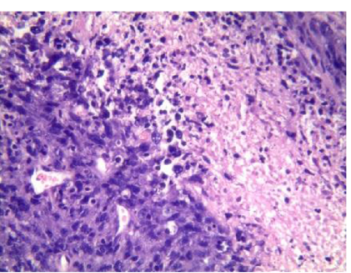

DNR

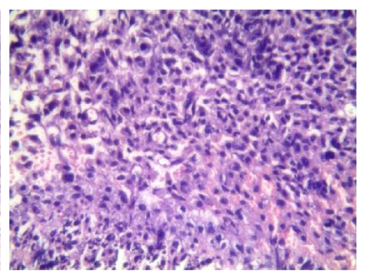

3BP 
The results of this study indicate that $3 \mathrm{BP}$ is a promising anti-tumorigenic drug that functions by activating multiple cell death pathways, and can potentially overcome tumor cell resistance to chemotherapeutic agents that activate a single cell death mechanism. Likewise, inhibiting glycolysis could be a point of anti-multi-resistant treatment, it remains to be subsequent research.

Acknowledgments This work was supported by the Natural Science Foundation of Anhui province (No. 1508085MH166), the National Science Foundation of China (No. 81372899, No. 81000992) and the Foundation of Bengbu Medical College (No.Byycx1432).

Conflicts of interest The authors declare that they have no conflict of interests regarding the publication of this paper.

Open Access This article is distributed under the terms of the Creative Commons Attribution 4.0 International License (http:// creativecommons.org/licenses/by/4.0/), which permits unrestricted use, distribution, and reproduction in any medium, provided you give appropriate credit to the original author(s) and the source, provide a link to the Creative Commons license, and indicate if changes were made.

\section{References}

Bellairs R (1961) Cell death in chick embryos as studied by electron microscopy. J Anat 95(54-60):53

Cardaci S, Desideri E, Ciriolo MR (2012) Targeting aerobic glycolysis: 3bromopyruvate as a promising anticancer drug. J Bioenerg Biomembr 44:17-29. doi:10.1007/s10863-012-9422-7

Chen Z, Zhang H, Lu W, Huang P (2009) Role of mitochondriaassociated hexokinase II in cancer cell death induced by 3bromopyruvate. Biochim Biophys Acta 1787:553-560. doi:10. 1016/j.bbabio.2009.03.003

Chesney J et al (1999) An inducible gene product for 6-phosphofructo-2kinase with an AU-rich instability element: role in tumor cell glycolysis and the Warburg effect. Proc Natl Acad Sci U S A 96:30473052

Cho YS, Challa S, Moquin D, Genga R, Ray TD, Guildford M, Chan FK (2009) Phosphorylation-driven assembly of the RIP1-RIP3 complex regulates programmed necrosis and virus-induced inflammation. Cell 137:1112-1123. doi:10.1016/j.cell.2009.05.037

Clarke PG (1990) Developmental cell death: morphological diversity and multiple mechanisms. Anat Embryol 181:195-213

da-Silva WS et al (2004) Mitochondrial bound hexokinase activity as a preventive antioxidant defense: steady-state ADP formation as a regulatory mechanism of membrane potential and reactive oxygen species generation in mitochondria. J Biol Chem 279:39846-39855. doi:10.1074/jbc.M403835200

Degterev A et al (2005) Chemical inhibitor of nonapoptotic cell death with therapeutic potential for ischemic brain injury. Nat Chem Biol 1:112-119. doi:10.1038/nchembio711

Du C, Fang M, Li Y, Li L, Wang X (2000) Smac, a mitochondrial protein that promotes cytochrome c-dependent caspase activation by eliminating IAP inhibition. Cell 102:33-42

Ferraro E et al (2008) Apoptosome-deficient cells lose cytochrome c through proteasomal degradation but survive by autophagydependent glycolysis. Mol Biol Cell 19:3576-3588. doi:10.1091/ mbc.E07-09-0858

Festjens N, Vanden Berghe T, Vandenabeele P (2006) Necrosis, a wellorchestrated form of cell demise: signalling cascades, important mediators and concomitant immune response. Biochim Biophys Acta 1757:1371-1387. doi:10.1016/j.bbabio.2006.06.014

Galluzzi L et al (2012) Molecular definitions of cell death subroutines: recommendations of the nomenclature committee on cell death 2012. Cell Death Differ 19:107-120. doi:10.1038/cdd.2011.96

Ganapathy-Kanniappan S et al (2010) 3-bromopyruvate: a new targeted antiglycolytic agent and a promise for cancer therapy. Curr Pharm Biotechnol 11:510-517

Geschwind JF, Ko YH, Torbenson MS, Magee C, Pedersen PL (2002) Novel therapy for liver cancer: direct intraarterial injection of a potent inhibitor of ATP production. Cancer Res 62:3909-3913

He S, Wang L, Miao L, Wang T, Du F, Zhao L, Wang X (2009) Receptor interacting protein kinase-3 determines cellular necrotic response to TNF-alpha. Cell 137:1100-1111. doi:10.1016/j.cell.2009.05.021

Jemal A, Bray F, Center MM, Ferlay J, Ward E, Forman D (2011) Global cancer statistics. CA Cancer J Clin 61:69-90. doi:10.3322/caac. 20107

Jin S, White E (2008) Tumor suppression by autophagy through the management of metabolic stress. Autophagy 4:563-566

Kabeya Y et al (2000) LC3, a mammalian homologue of yeast Apg8p, is localized in autophagosome membranes after processing. EMBO J 19:5720-5728. doi:10.1093/emboj/19.21.5720

Komatsu M et al (2006) Loss of autophagy in the central nervous system causes neurodegeneration in mice. Nature 441:880-884. doi:10. 1038/nature 04723

Kuma A et al (2004) The role of autophagy during the early neonatal starvation period. Nature 432:1032-1036. doi:10.1038/nature03029

Leist M, Single B, Castoldi AF, Kuhnle S, Nicotera P (1997) Intracellular adenosine triphosphate (ATP) concentration: a switch in the decision between apoptosis and necrosis. J Exp Med 185:1481-1486

Levy AG et al (2012) The combination of the novel glycolysis inhibitor 3$\mathrm{BrOP}$ and rapamycin is effective against neuroblastoma. Invest New Drugs 30:191-199. doi:10.1007/s10637-010-9551-y

Li P, Nijhawan D, Budihardjo I, Srinivasula SM, Ahmad M, Alnemri ES, Wang X (1997) Cytochrome c and dATP-dependent formation of Apaf-1/caspase-9 complex initiates an apoptotic protease cascade. Cell 91:479-489

Liu XH, Zheng XF, Wang YL (2009) Inhibitive effect of 3-bromopyruvic acid on human breast cancer MCF-7 cells involves cell cycle arrest and apoptotic induction. Chin Med J (Engl) 122:1681-1685

Liu $\mathrm{Z}$ et al (2014) 3-Bromopyruvate induces apoptosis in breast cancer cells by downregulating Mcl-1 through the PI3K/Akt signaling pathway. Anticancer Drugs 25:447-455. doi:10.1097/CAD. 0000000000000081

Lockshin RA, Zakeri Z (2007) Cell death in health and disease. J Cell Mol Med 11:1214-1224. doi:10.1111/j.1582-4934.2007.00150.x

Lukens JR, Vogel P, Johnson GR, Kelliher MA, Iwakura Y, Lamkanfi M, Kanneganti TD (2013) RIP1-driven autoinflammation targets IL1alpha independently of inflammasomes and RIP3. Nature 498: 224-227. doi:10.1038/nature 12174

Mathew R, White E (2011) Autophagy in tumorigenesis and energy metabolism: friend by day, foe by night. Curr Opin Genet Dev 21:113119. doi:10.1016/j.gde.2010.12.008

Mathiasen IS, Jaattela M (2002) Triggering caspase-independent cell death to combat cancer. Trends Mol Med 8:212-220

Mizushima N, Komatsu M (2011) Autophagy: renovation of cells and tissues. Cell 147:728-741. doi:10.1016/j.cell.2011.10.026

Mortensen $\mathrm{M}$ et al (2011) The autophagy protein Atg7 is essential for hematopoietic stem cell maintenance. J Exp Med 208:455-467. doi: 10.1084/jem.20101145

Narendra D, Tanaka A, Suen DF, Youle RJ (2008) Parkin is recruited selectively to impaired mitochondria and promotes their autophagy. J Cell Biol 183:795-803. doi:10.1083/jcb.200809125

Ota S, Geschwind JF, Buijs M, Wijlemans JW, Kwak BK, GanapathyKanniappan S (2013) Ultrasound-guided direct delivery of 3bromopyruvate blocks tumor progression in an orthotopic mouse 
model of human pancreatic cancer. Target Oncol 8:145-151. doi:10. 1007/s11523-013-0273-x

Parks SK, Mazure NM, Counillon L, Pouyssegur J (2013) Hypoxia promotes tumor cell survival in acidic conditions by preserving ATP levels. J Cell Physiol 228:1854-1862. doi:10.1002/jcp.24346

Peter ME, Krammer PH (2003) The CD95(APO-1/Fas) DISC and beyond. Cell Death Differ 10:26-35. doi:10.1038/sj.cdd.4401186

Schweichel JU, Merker HJ (1973) The morphology of various types of cell death in prenatal tissues. Teratology 7:253-266. doi:10.1002/ tera. 1420070306

Shoshan MC (2012) 3-Bromopyruvate: targets and outcomes. J Bioenerg Biomembr 44:7-15. doi:10.1007/s10863-012-9419-2

Simonnet $\mathrm{H}$ et al (2002) Low mitochondrial respiratory chain content correlates with tumor aggressiveness in renal cell carcinoma. Carcinogenesis 23:759-768

Takahashi A et al (2012) Autophagy guards against cisplatin-induced acute kidney injury. Am J Pathol 180:517-525. doi:10.1016/j. ajpath.2011.11.001

Tanida I, Ueno T, Kominami E (2004) LC3 conjugation system in mammalian autophagy. Int J Biochem Cell Biol 36:2503-2518. doi:10. 1016/j.biocel.2004.05.009

Thapa RJ et al (2013) Interferon-induced RIP1/RIP3-mediated necrosis requires PKR and is licensed by FADD and caspases. Proc Natl Acad Sci U S A 110:E3109-3118. doi:10.1073/pnas.1301218110
Verhagen AM et al (2000) Identification of DIABLO, a mammalian protein that promotes apoptosis by binding to and antagonizing IAP proteins. Cell 102:43-53

Warburg O (1928) The chemical constitution of respiration ferment. Science 68:437-443. doi:10.1126/science.68.1767.437

Warburg O (1956) On the origin of cancer cells. Science 123:309-314

$\mathrm{Xu} \mathrm{RH}$ et al (2005) Inhibition of glycolysis in cancer cells: a novel strategy to overcome drug resistance associated with mitochondrial respiratory defect and hypoxia. Cancer Res 65:613-621

Yuan J, Kroemer G (2010) Alternative cell death mechanisms in development and beyond. Genes Dev 24:2592-2602. doi:10.1101/gad. 1984410

Zhang DW et al (2009a) RIP3, an energy metabolism regulator that switches TNF-induced cell death from apoptosis to necrosis. Science 325:332-336. doi:10.1126/science.1172308

Zhang Q et al (2014) Hexokinase II inhibitor, 3-BrPA induced autophagy by stimulating ROS formation in human breast cancer cells. Genes Cancer 5:100-112

Zhang X et al (2009b) Novel therapy for malignant pleural mesothelioma based on anti-energetic effect: an experimental study using 3Bromopyruvate on nude mice. Anticancer Res 29:1443-1448

Zuo X, Djordjevic JT, Bijosono Oei J, Desmarini D, Schibeci SD, Jolliffe KA, Sorrell TC (2011) Miltefosine induces apoptosis-like cell death in yeast via Cox9p in cytochrome c oxidase. Mol Pharmacol 80: 476-485. doi:10.1124/mol.111.072322 